\title{
Toxicity study of new metal nanoparticles functionalized with fluorescein derivatives as novel image systems
}

\author{
A. Fernandéz-Lodeiro***, J. Fernandéz-Lodeiro**, C. Nuñez***, E. Oliveira*, H.M. Santos***, \\ C. Lodeiro****, J.L. Capelo**** and M.S. Diniz* \\ *REQUIMTE, Departamento de Química, Faculdade de Ciências e Tecnologia, Centro de Química Fina e \\ Biotecnologia, Universidade Nova de Lisboa, 2829-516 Caparica. \\ **BIOSCOPE Group, Physical-Chemistry Department, Faculty of Science, Campus Ourense, University of \\ Vigo, 32004, Ourense, Spain.
}

Nanoparticles in general (NPs) and/or nanomaterials offer remarkable opportunities in industrial production, daily consumables, medicine, biotechnology, electronics and numerous other important commercial and economical areas. Among all these areas, nanomedicine has opened novel treatments for problematic diseases such as viral, genetic, cancer, AIDS, etc. There is limited information available regarding translocation and distribution of NPs in the body and in the environment. Additionally, there is also need for more information on NPs toxicity. Recently has been demonstrated that physiological barriers such as pulmonary and gastro-intestinal tract are affected $[1,2]$.

The main objective of this work is to use functionalized metal NPs, as emissive agent markers, assess their internalization in cells and evaluate toxicity to cells.

Using the emissive two probes synthesized in a one-pot reaction using fluoresceine as chromophore, several gold $(\mathrm{Au})$, round shape, and silver $(\mathrm{Ag}) \mathrm{NPs}$ (round and triangular shapes) were functionalized in organic media and water by Brust [3] and Turkevish [4] methodology, using tetraoctylammonium bromide (TOABr) as a common stabilizer and sodium borohydride as reducing agent. All has been characterized by UV-vis and emission spectroscopy, transmission electron microscopy (TEM) (Figure 1), and Light scattering. To study the route of internalization into the cell NP-complexes were injected intraperitoneally in fish (Carassius auratus). After 48 hour fish were sampled and sacrificed and liver and intestine processed for histology examination [5]. Additional sub-samples were stored at $-80^{\circ} \mathrm{C}$ for enzymatic analysis (glutathione-S-transferase and catalase) [6,7]. Blood was also collected from healthy non-injected fish, for leucocyte separation followed by incubation with the metal NPs and cell viability assays [8]. The presence of emissive NPs in cells was examined by microscopy using a Leica microscope (ATC 2000) adapted for epifluorescence (EF).

The microscopy analysis showed that apparently both metal NPs were internalized by leucocytes and intestine cells (Figure 2a and 2b) but apparently not by hepatocytes. However, it is still to clarify if NPs internalization occurred in dead or dying cells only, with more permeable membranes, or also in living cells. Another possibility relates to the detection limits and resolution of the microscope used: the fraction of NPs entering is too low and not detectable with this type of equipment. No significant fluorescence was detected in controls. Viability assays showed higher mortality rates in leucocytes incubated with triangular Ag NPs suggesting that the type of metal and shape have influence in cell toxicity. In general, enzymatic assays indicate low oxidative stress for cells. However, GST results show significant $(\mathrm{p}<0.05)$ differences in livers from fish injected with round Ag NPs. With respect to catalase, significant differences $(p<0.05)$ were detected in livers from fish injected with round $\mathrm{Au}$ NPs. Although the presented results are preliminary they suggest that functionalized NPs are able to penetrate cell membranes. On the other hand, the observed toxicity can be attributed to differences in shape and type of metal NPs.

The authors acknowledge the funding by Fundação para a Ciência e Tecnologia through grant PTDC/MAR/1 19068/2010 and through project no. PEst-C/EQB/LA0006/2011 granted to Requimte.

References

[1] Frank N. et al., J. Chem. Educ., 87:1098-1101, 2010.

[2] Monge M., Ann. Quím., 105:33-41, 2009. 
[3] Brust M. et al., J. Chem. Soc. Chem. Commun., 7:801-802, 1994.

[4] Turkevich J. et al., Discuss. Faraday Soc. 11:55-75, 1951.

[5] Martoja R. and Martoja-Pierson M ., in "Initiation aux techniques de l'histologie animale". Issy-lesMoulineaux, France Masson. 345p., 1967.

[6. Maehly E.M. and Chance B., Meth. Biochem. Ana., 1:357-424, 1954.

[7] Habig W.H. et al., J. Biol. Chem., 249:7130-7139, 1974.

[8] Fernandez-Botran F. and Vetvicka V., in "Advanc Method Cell Immunol”, CRC Press, Boca Raton, 9, 2000.
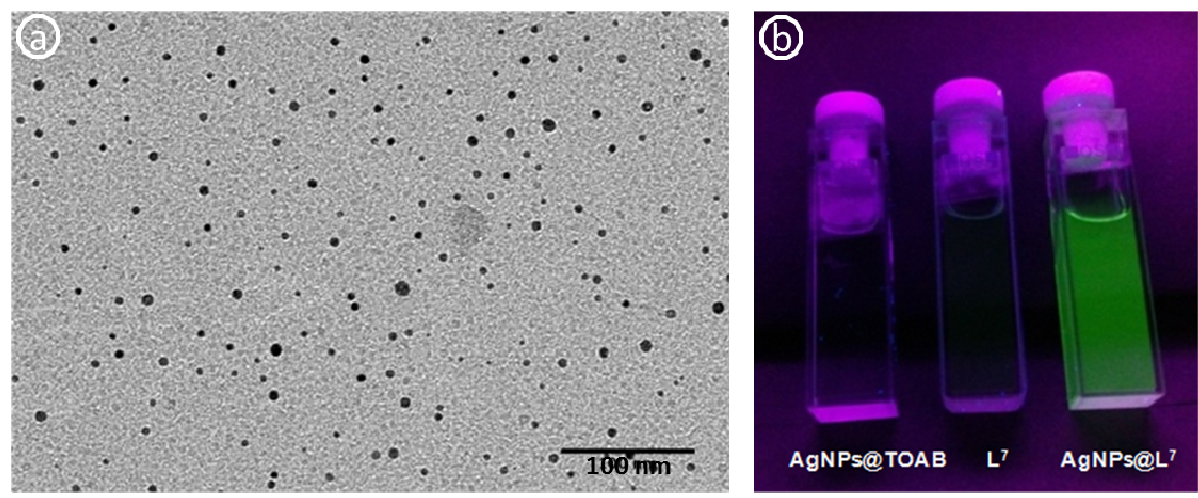

Figure 1. (a) TEM image of Ag NPs, AgNP $@$ @TOAB. (b) AgNP $@$ @SHFluoresceine under UV light.

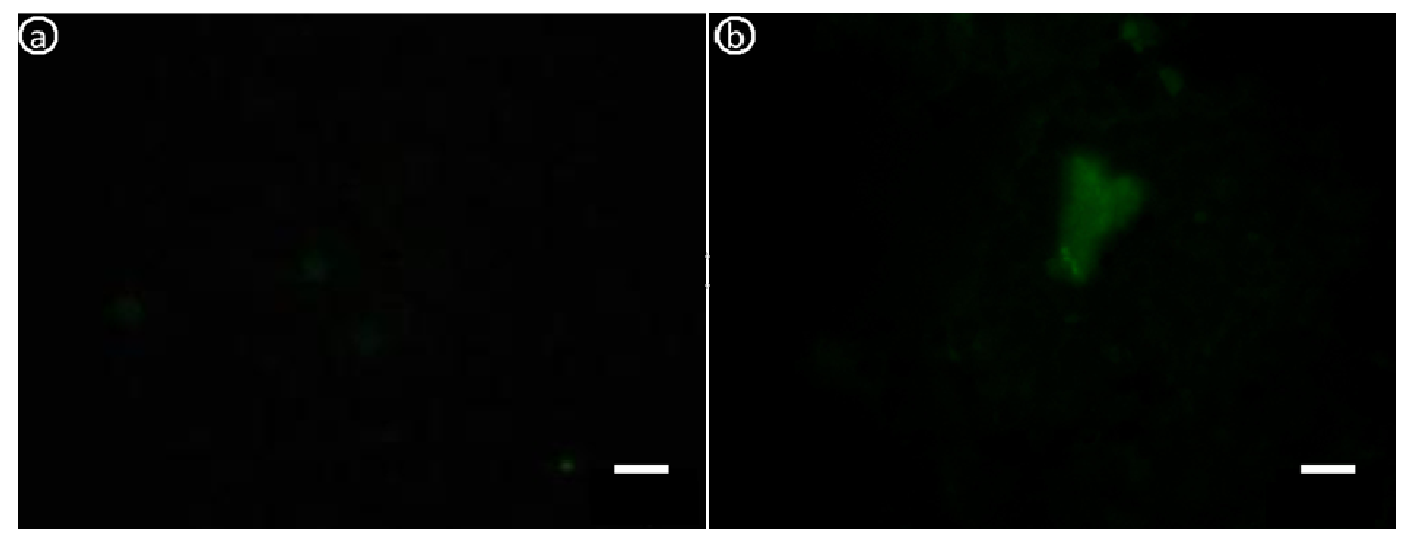

Figure 2. (a) Leucocytes with emissive Ag NPs. (b) Emissive Ag NPs in intestine cells. 